\title{
Major trends in knowledge management research: a bibliometric study
}

Article in Scientometrics · June 2016

DOI: $10.1007 / \mathrm{s} 11192-016-1938-x$

CITATIONS

33

4 authors:

Peyman Akhavan

Malek Ashtar University of Technology

127 PUBLICATIONS 833 CITATIONS

SEE PROFILE

Mahdieh Fetrati

Aalborg University

1 PUBLICATION 33 CITATIONS

SEE PROFILE

Nader Ale Ebrahim

University of Malaya

284 PUBLICATIONS $\quad \mathbf{1 , 2 8 9}$ CITATIONS

SEE PROFILE

\section{Amir Pezeshkan}

University of Baltimore

16 PUBLICATIONS 69 CITATIONS

SEE PROFILE

Some of the authors of this publication are also working on these related projects:

Evaluating the Relationships between Organizational Knowledge Creation Theory and Organizational Performance View project 


\section{Major trends in knowledge management research: a bibliometric study}

\section{Peyman Akhavan, Nader Ale Ebrahim, Mahdieh A. Fetrati \& Amir Pezeshkan}

\section{Scientometrics}

An International Journal for all Quantitative Aspects of the Science of Science, Communication in Science and Science Policy

ISSN 0138-9130

Scientometrics

DOI 10.1007/s11192-016-1938-x

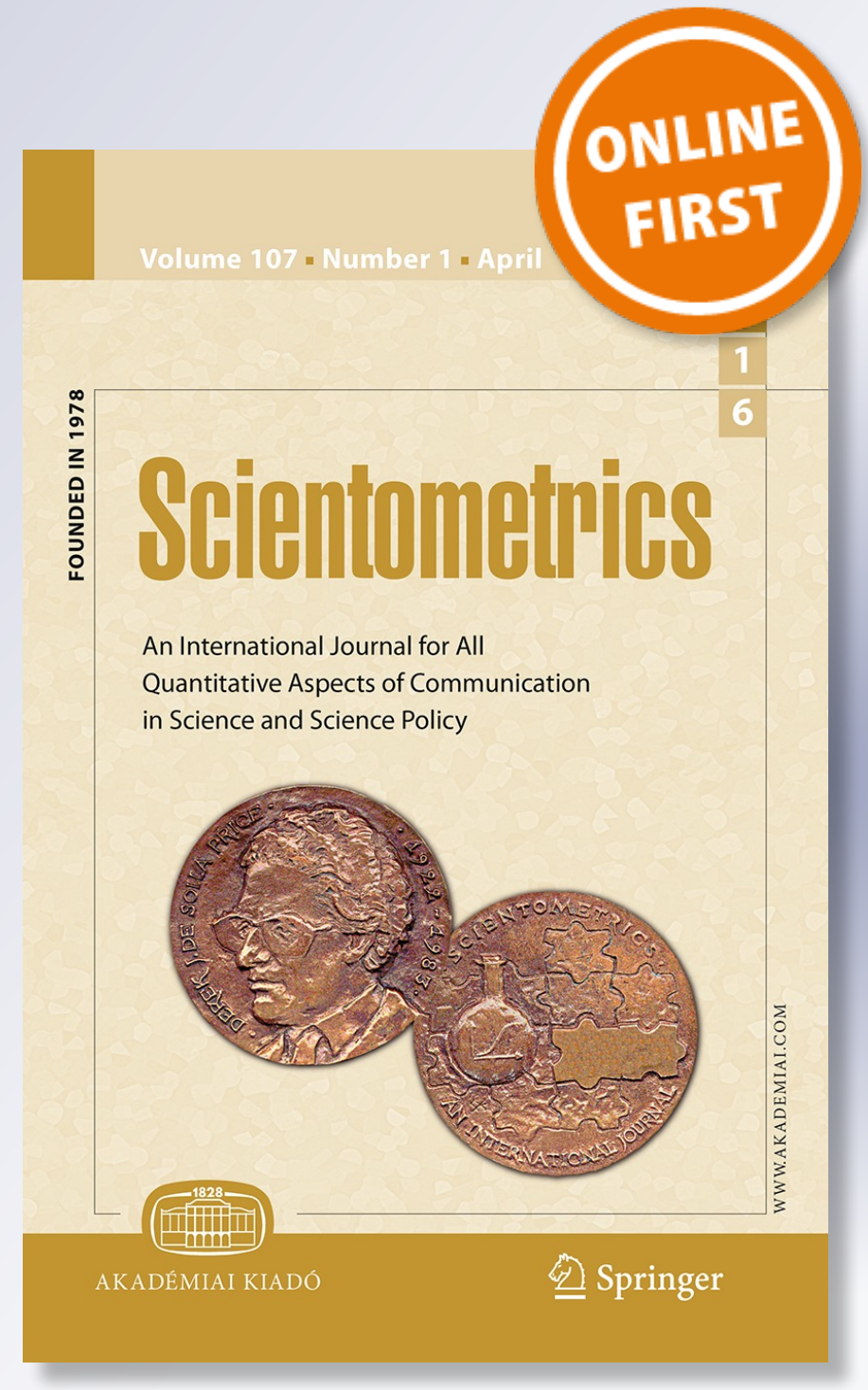

囪 Springer 
Your article is protected by copyright and all rights are held exclusively by Akadémiai Kiadó, Budapest, Hungary. This e-offprint is for personal use only and shall not be selfarchived in electronic repositories. If you wish to self-archive your article, please use the accepted manuscript version for posting on your own website. You may further deposit the accepted manuscript version in any repository, provided it is only made publicly available 12 months after official publication or later and provided acknowledgement is given to the original source of publication and a link is inserted to the published article on Springer's website. The link must be accompanied by the following text: "The final publication is available at link.springer.com". 


\title{
Major trends in knowledge management research: a bibliometric study
}

\author{
Peyman Akhavan $^{1}$ - Nader Ale Ebrahim ${ }^{2} \cdot$ Mahdieh A. Fetrati $^{3}$. \\ Amir Pezeshkan ${ }^{4}$
}

Received: 28 September 2015

(C) Akadémiai Kiadó, Budapest, Hungary 2016

\begin{abstract}
This study provides an overview of the knowledge management literature from 1980 through 2014. We employ bibliometric and text mining analyses on a sample of 500 most cited articles to examine the impact of factors such as number of authors, references, pages, and keywords on the number of citations that they received. We also investigate major trends in knowledge management literature including the contribution of different countries, variations across publication years, and identifying active research areas and major journal outlets. Our study serves as a resource for future studies by shedding light on how trends in knowledge management research have evolved over time and demonstrating the characteristics of the most cited articles in this literature. Specifically, our results reveal that the most cited articles are from United States and United Kingdom. The most prolific year in terms of the number of published articles is 2009 and in terms of the number of citations is 2012. We also found a positive relationship between the number of publications' keywords, references, and pages and the number of citations that they have received.
\end{abstract}

Nader Ale Ebrahim, Mahdieh A. Fetrati and Amir Pezeshkan have contributed equally to this work.

Peyman Akhavan

peyman_akv@yahoo.com

Nader Ale Ebrahim

aleebrahim@um.edu.my

Mahdieh A. Fetrati

m_afetrati@yahoo.com

Amir Pezeshkan

apezeshkan@ubalt.edu

1 Department of Management, Malek Ashtar University of Technology, Tehran, Iran

2 Department of Engineering Design and Manufacture, University of Malaya, Kuala Lumpur, Malaysia

3 Aalborg University, Aalborg, Denmark

4 Department of Management and International Business, Merrick School of Business, University of Baltimore, Baltimore, MD 21201, USA 
Finally, the Journal of Knowledge Management has the largest share in publishing the most cited articles in this field.

Keywords Bibliometric $\cdot$ Citation analysis $\cdot$ Knowledge management $\cdot$ Research productivity

\section{Introduction}

Bibliometric analysis which refers to combining different frameworks, tools, and methods to study and analyze citations of scholarly publications, has led to development of different metrics to gain insights into the intellectual structure of a broad academic discipline and evaluate the impact of scientific journals, studies, and researchers according (Ponce and Lozano 2010). Science Citation Index, developed by the Institute for Scientific Information (ISI) in 1962 and later owned by Thomson Reuters (Tsai et al. 2006), facilitated conducting bibliometric studies to a great extent (Garfield 1972) and made it a popular tool to evaluate research groups, publications, and journals (Thelwall 2008). Thomson Reuters' Web of Science (WoS) is a structured database that indexes selected publications from various disciplines.

Empirical evaluations of science and technology research which have become more feasible due to development of databases such as WoS, play a crucial role in creating effective science policies (So et al. 2015). The results of bibliometric analysis can shed light on factors that strengthen the contribution of studies in a research area and guide scholars towards producing impactful studies. In such evaluations, the number of papers published and the number of citations received represent two of the most important indicators of an impactful contribution (Ida and Fukuzawa 2013; Wildgaard 2015). In general, there is a significant positive relationship between the number of citations that a paper receives and the general perception with regard to its quality (Marks 2001).

Bibliometric and citation analyses have been vastly adopted by prior studies in management research (e.g., Bjørnson and Dingsøyr 2008; Guo and Sheffield 2008; Qiu and Lv 2014; Kane et al. 2006; Karami et al. 2006; Rezazadeh Mehrizi and Bontis 2009; Schultze and Leidner 2002; Schultze and Stabell 2004). For instance, Scandura and Williams (2000) examined research trends in management by comparing all articles published in the Academy of Management Journal, Administrative Science Quarterly, and the Journal of Management during a three-year period in the 1980s with the articles published during a comparable three-year period in the 1990s to demonstrate how those trends had evolved and changed.

Particularly in knowledge management (KM) stream, Gu (2004) conducted a general bibliometric analysis on 1407 global KM publications published during 1975-2004. Results revealed a significant relationship between citation frequency of the articles and impact factor of publisher outlet and no significant impact from authorship pattern. Qiu and Lv (2014) conducted one of the latest bibliometric study in KM literature answering a number of research questions pertaining to patterns such as subject categories, keywords frequencies, and international collaboration. However, the major constraint of this study was using a single key word, "knowledge management", to retrieve articles from the WoS database which limited the inclusion of their sample and their power to capture more relevant KM studies. Also, Serenko and Bontis (2013), and Serenko and Dumay (2015a, b) 
are among a few recent attempts to analyze the stock of KM publications and identify "citation classics" in KM field. However, they have selected a narrow scope and have concentrated on a limited number of articles from a restricted list of outlets.

In addition to bibliometrics, prior research has utilized other methods and approaches to study the major trends, findings, and implications of KM studies. For instance, Serenko and Bontis (2013) applied meta-analysis technique to integrate the overall findings of KM articles. Also, there are several studies identifying and examining the influential KM publications which have a narrow focus and do not cover a wide variety of the KM literature (Nonaka and Peltokorpi 2006; Ponzi 2002; Serenko et al. 2010). Literature reviews constitute another group of prior studies attempting to integrate past literature on knowledge management. For instance, Crilly et al. (2009) conducted a literature review on a selected range of KM studies and Nicolini et al. (2008) reviewed KM studies in healthcare sector.

Although all of these studies enhance our understanding of KM research, according to Serenko (2013), a brief overview of these works reveals that many KM researchers are not fully aware of prior publications from a scientometric perspective. With KM becoming an independent research domain and emergence of journals such as Journal of Knowledge Management dedicated to KM studies, there is a need to identify influential factors that have made KM studies more visible and subsequently impactful in the literature. This study is an attempt to address this issue by conducting a comprehensive research on a large sample of KM publications. We reviewed various outlets to collect the most relevant KM articles published between 1980 and 2014. Then we analyzed the articles based on the country of origin, publication year, number of authors, number of references, number of pages, number of keywords, research areas, and publisher outlet to explore the major trends in $\mathrm{KM}$ studies and factors impacting the number of citations received by them. In following sections, we first describe our methodology and then report our findings and discuss their implications for future research.

\section{Methodology}

To draw our sample and following prior literature, we first conducted a comprehensive search to collect published KM scientometric studies (Gu 2004; Qiu and Lv 2014). We collected our data from the "Web of Science Core Collection" that includes "SCIEXPANDED", "SSCI", "A\&HCI", "CPCI-S", and "CPCI-SSH" to include articles with an acceptable level of quality (Gu 2004). The result of our search spans from 1980 to 2014. We utilized Boolean combinations of knowledge management keywords to retrieve relevant articles. Our first attempt using the keyword, "knowledge", included in the title yielded 103,458 articles. Further, we identified 62 different keywords that had frequently appeared in the title of papers in our initial sample and were directly related to KM stream. We based our final search on this inclusive set of keywords which resulted in in a sample of 3198 articles:

- Knowledge (consist of 49 different variations, such as: knowledge management, tacit knowledge, explicit knowledge, knowledge sharing, knowledge retrieval, knowledge acquisition, knowledge elicitation, knowledge capture, knowledge engineering, knowledge organizing, knowledge process, knowledge creation, knowledge transfer, knowledge application, knowledge audit, knowledge base, knowledge methods, knowledge productivity, knowledge quality, knowledge foresight, knowledge 
repository, knowledge worker, knowledge active forgetting, knowledge asset, knowledge culture, knowledge society, knowledge market, knowledge broker, knowledge based organization, knowledge performance, knowledge education, knowledge network, knowledge strategy, knowledge map, knowledge model, and knowledge based system).

- Learning organization

- Organizational learning

- Community of practice

- After action review

- Lessons learned

- Story telling

- Intellectual capital

- Intangible asset

- Intellectual property

- Structural capital

- Relational capital

- Human capital

- Elements of SECI model (Socialization-externalization-combination-Internalization)

After drawing the final sample, we designed our measurement of the number of citations that studies in our sample had received. The key issue in measuring the citations is that the time elapsed since publication significantly impacts the number of citations that articles receive (Eshraghi et al. 2013). To avoid this bias, we designed and calculated a citation index for each study as the average number of citations per year. Then, we ranked the studies in our sample based on this index to identify top 500 articles with highest citation index. We used this sub-sample for our core analyses. However, for more general analyses full sample (i.e., 3198 studies) has been used as described in the result section.

\section{Results}

\section{Bibliometric analysis based on publication year and country ${ }^{1}$}

The first trend that we describe is the time trend of KM publications in our sample. As demonstrated by Fig. 1, the number of publications increases with a very slow rate from year 1987 to 2006, but there is a sudden significant surge in 2007 indicating that in a short period around 2007, KM topics have drawn much attention among management scholars. The number of publications in 2007 accounts for $12 \%$ of the entire sample.

Further, we classified the articles based on their country of origin using authors' affiliation. We must note that to maintain consistency, we excluded multi-authored articles in which authors had collaborated from different countries (273 articles) from this analysis.

As reported in Table 1, countries such as China, United States (US), United Kingdom (UK), Malaysia, Australia, Taiwan, Spain, Italy, Germany and Canada have the highest number of articles.

\footnotetext{
${ }^{1}$ In this section of the paper (Sect. 3.1) years 2013/14 are removed in figures because it is possible that not these years' works were located (because of time lag which is a common problem of all indexes and databases). However, the full dataset is used for calculations because the error is likely to be randomly/ evenly distributed. Thus the full sample of 3198 articles been used for all non-longitudinal types of statistical analyses.
} 


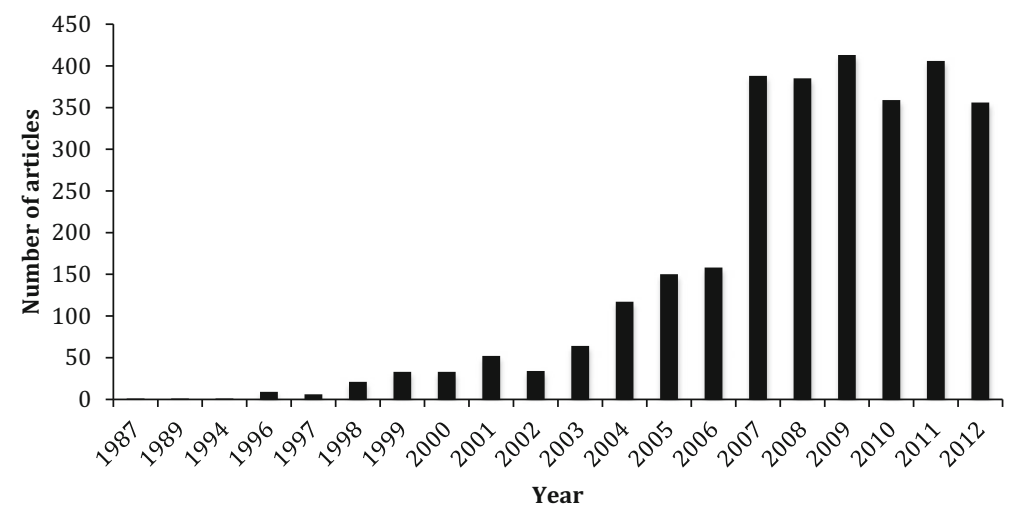

Fig. 1 Number of KM publications per year

Table $1 \mathrm{KM}$ publications and most cited studies published in various countries

\begin{tabular}{lllll}
\hline Country & $\begin{array}{l}\text { A: Number of } \\
\text { publication } \\
\text { (entire sample) }\end{array}$ & Country & $\begin{array}{l}\text { B: Number of highly } \\
\text { cited papers (top 500 } \\
\text { papers) }\end{array}$ & $\begin{array}{l}\text { Percentage (Ratio of } \\
\text { B/A for each country) } \\
(\%)\end{array}$ \\
\hline China & 668 & US & 162 & 44.62 \\
US & 363 & UK & 73 & 28.85 \\
UK & 253 & Taiwan & 19 & 18.63 \\
Malaysia & 138 & Canada & 15 & 24.59 \\
Australia & 106 & Spain & 14 & 16.09 \\
Taiwan & 102 & Australia & 10 & 9.43 \\
Spain & 87 & Italy & 10 & 13.33 \\
Italy & 75 & Netherland & 10 & 20 \\
Germany & 66 & China & 9 & 1.35 \\
Canada & 61 & South Korea & 8 & 29.63 \\
Iran & 56 & France & 7 & 14.29 \\
Netherland & 50 & Germany & 7 & 10.61 \\
India & 49 & Israel & 7 & 58.33 \\
France & 49 & New Zealand & 6 & 26.09 \\
Finland & 45 & Denmark & 5 & 29.41 \\
\hline
\end{tabular}

To provide a comprehensive picture of KM research across different countries, Fig. 2 specifies various countries on the map based on total number of citations that articles from each country have received. China, US, and UK have the highest number of KM publications. In Asia, India and Iran are among the countries focusing more on KM topics while developed countries such as Japan have not been as prolific in this continent. In Africa, the major country producing KM research is Nigeria and to a lower extent South Africa. An interesting observation is that despite the high number of KM publications in countries such as Russia, China, and some South American countries, the number of citations that studies from these countries have received is not substantial. For instance, China has the highest number of publications, but less than $2 \%$ of its articles are among the 500 most cited articles. Similarly, Malaysia is located in the fourth place with regard to the number 


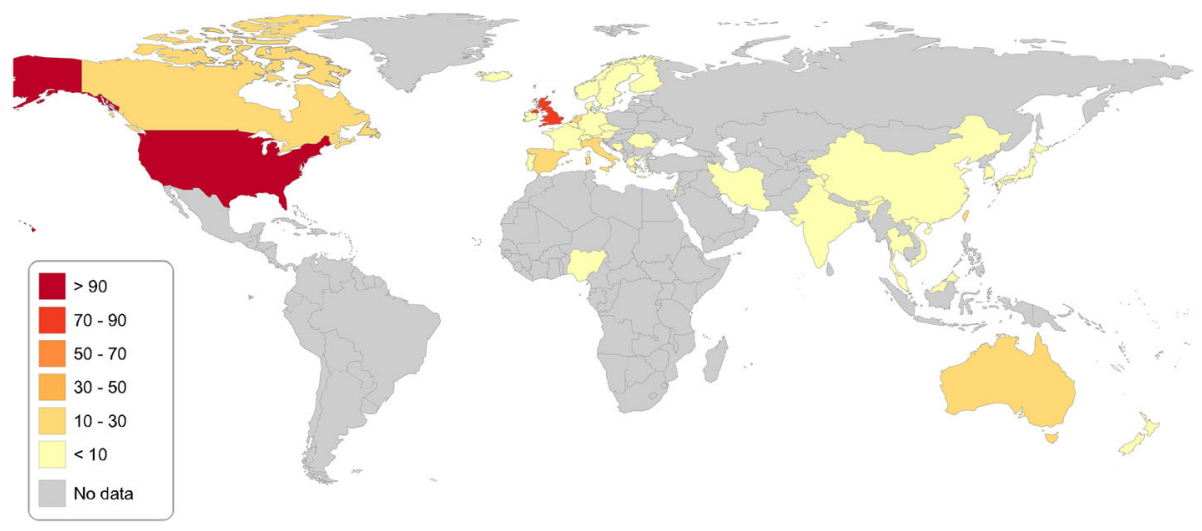

Fig. 2 Number of most cited KM publications across different countries

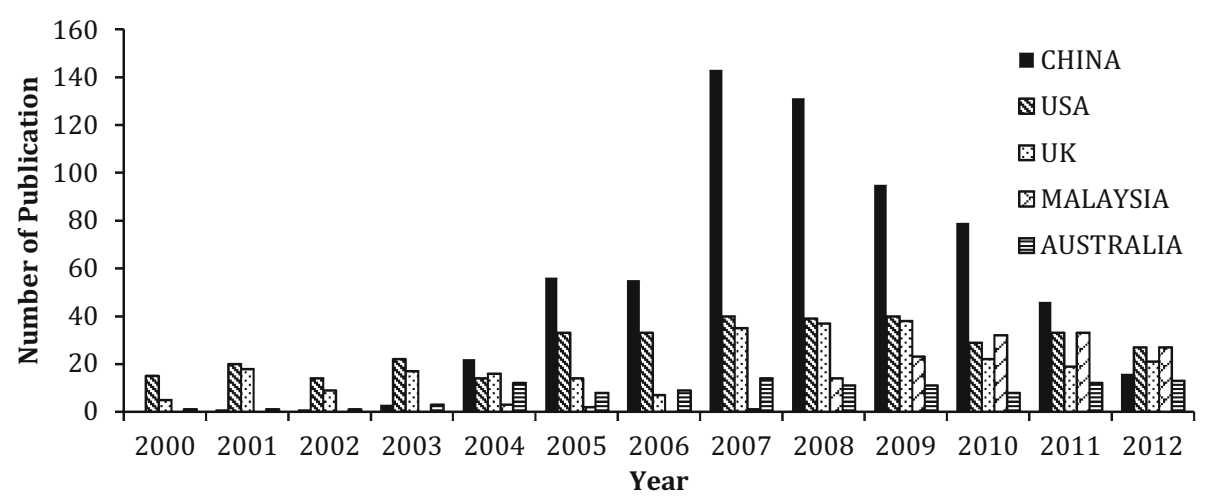

Fig. 3 Number of KM publications based on year/country

of publications but it only has one article ( $0.7 \%$ of total articles) among the top 500 articles. On the other hand, more than $40 \%$ of articles from US are among the most cited articles. Interestingly, although South Korea and Netherland are not among the countries with a large number of publications, a significant proportion of their articles have been highly cited. There are two plausible factors leading to this issue. First, the average quality of research produced in countries such as China and Malaysia has limited their citation by other researchers. Second, researchers from such countries may lack exposure to the global network of KM scholars which may have also contributed to their low level of received citations.

To investigate the temporal trend of KM publications, we designed Fig. 3 to show the number of publications per year for five countries with the highest number of publications. For instance, the first publication of Chinese researchers was in 2004 and the highest rate of publications from China has occurred in 2007 (138 articles) which is a significant contributor to the sudden surge in the total number of publications reported in Fig. 1. It also can explain why China was not included in prior KM bibliometric studies conducted before 2004 (e.g., Gu 2004). 


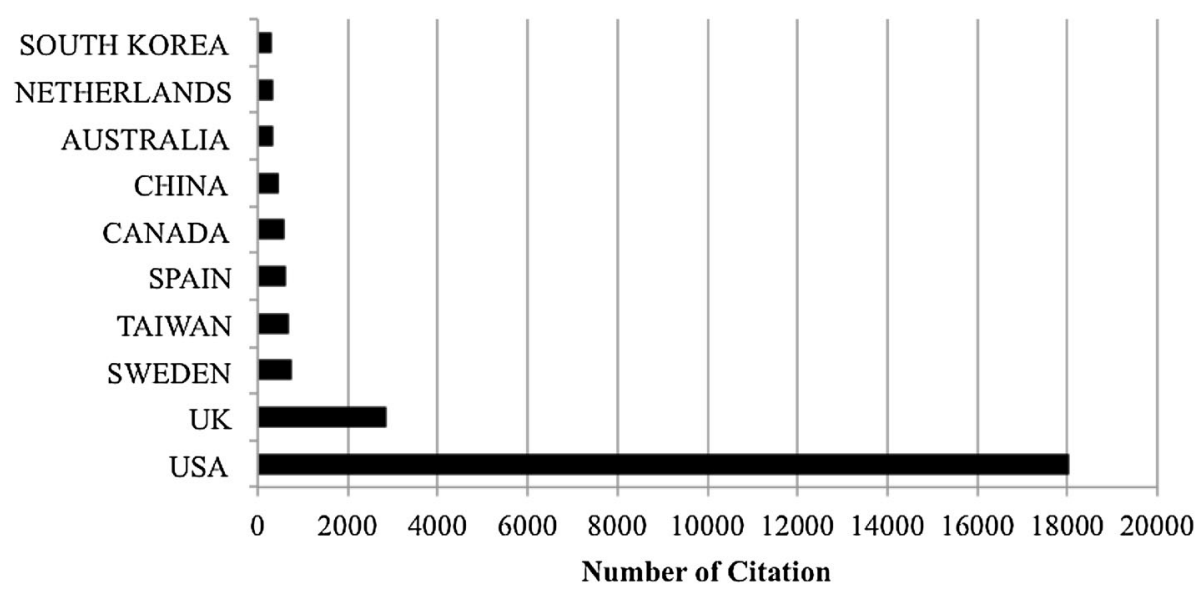

Fig. 4 Total number of citations based on the country of origin

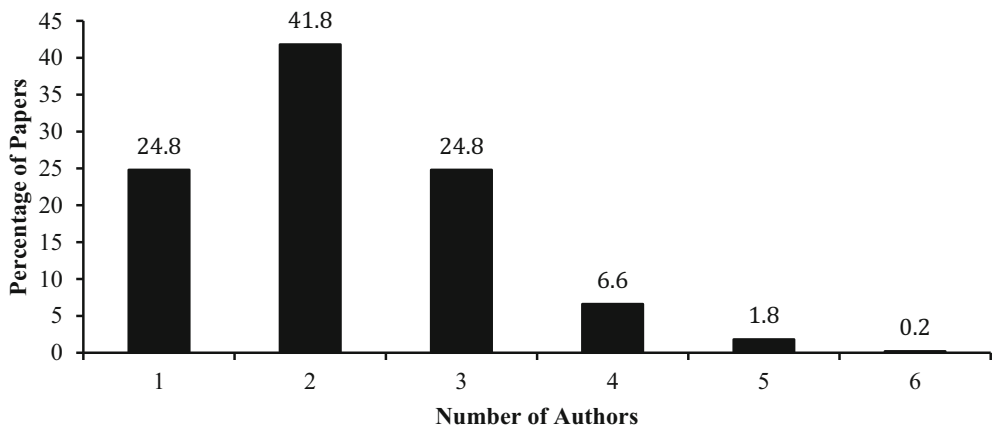

Fig. 5 Distribution of KM publications based on number of author(s)

Figure 4 shows the number of citations that publications from prolific countries in KM research have received. This information can be used to compare the impact and visibility of articles produced across various nations. Comparing Figs. 3 and 4, it is evident that while the number of studies are disproportionately increasing in some countries such as China and Malaysia but the number of citations is still highest for research done in other countries such as US and UK.

\section{Number of authors and number of citations}

To conduct a deeper analysis in this section, we focus on the 500 most cited papers. There are 1015 unique authors associated with these 500 articles. The average number of authors per study in our sample is 2.194 with standard deviation of 0.955 . Figure 5 demonstrates distribution of publications based on the number of co-authors. Similar to Serenko et al. (2010), we found a decline in single-authored works over time and emergence of a collaboration trend among KM scholars evident by both Figs. 5 and 6. 


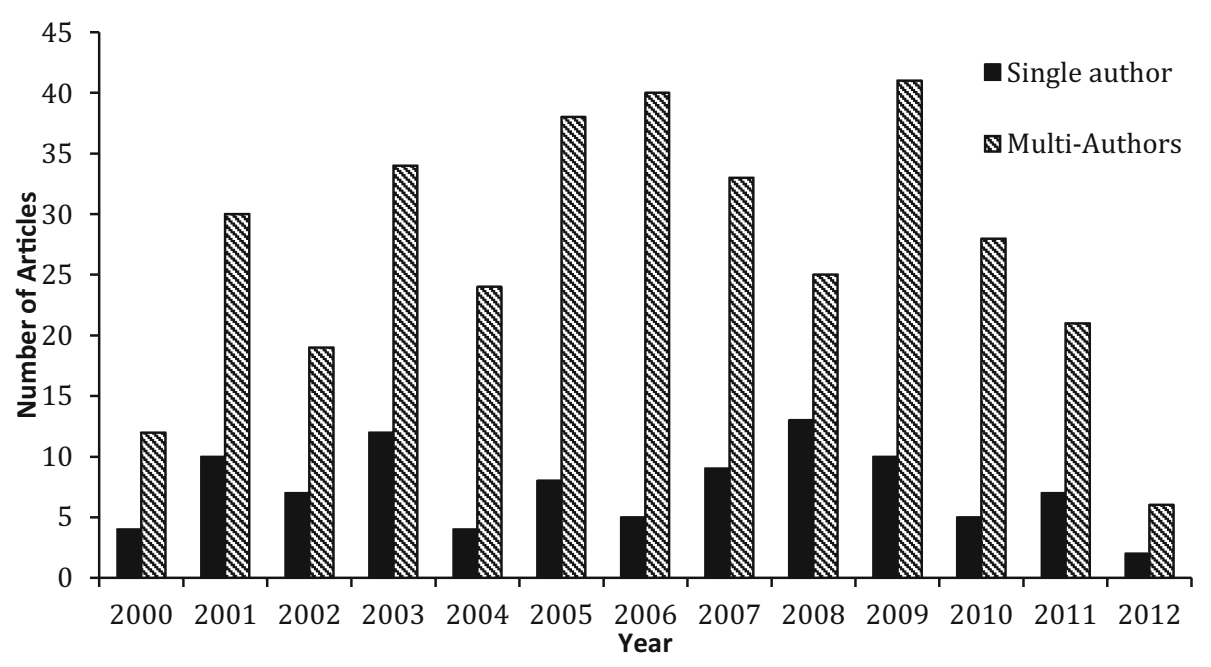

Fig. 6 The number of solo/multi authored KM publications per year

Figure 6 reports the number of single versus multi-authored publications per year from 2000 to 2012. It is evident that the number of studies published by multiple authors is significantly greater than the number of single authored publications.

With regard to the impact of number of authors collaborating in a study, it is important to examine whether there is a significant relationship between the number of authors and the number of citations that a study has received. We conducted an ANOVA test to answer this question. Doing so, we split the sample into two groups: single-authored and multiauthored articles to compare the mean value of citation index between two groups. According to the results, the $F$-value is 0.0804 ( $p$ value 0.7768 ) which indicates there is no significant difference between the mean values of the citation index of single and multiauthored papers.

As a robustness test, we grouped the articles with the same number of authors and conducted ANOVA to examine whether there is a significant difference among the groups with respect to the number of citations. The test yielded the same results and no significant differences was observed.

\section{Keywords and number of citations}

So et al. (2015) in their bibliometric study on science and technology publications found that there is a positive and significant correlation between the number of keywords and the number of citations. To examine whether there is such relationship in our sample, first, we grouped the articles in our sample based on the number of keywords. Then we employed ANOVA to compare the mean values of citation index across different groups. The minimum, maximum, mean value, and standard deviation of keywords (for the 500 most cited publications) are $0,13,3.678$, and 2.494, respectively. Studies in our sample have used 1819 unique keywords. ${ }^{2}$ The most common words, as reported in Table 2, are knowledge, management, organizational, and learning.

\footnotetext{
${ }^{2}$ The total number of words was 3645 because some of the keywords consist of multiple words.
} 
Table 2 Frequency of the major keywords among the 500 most cited publications

\begin{tabular}{lcc}
\hline Words & Number of use & Total number of citation \\
\hline Knowledge & 599 & 22,144 \\
Management & 433 & 20,659 \\
Organization & 100 & 7899 \\
Learning & 47 & 4971 \\
Systems & 64 & 3298 \\
\hline
\end{tabular}

Our ANOVA test resulted in the $F$-value of 1.9683 ( $p$ value 0.0253 ). Therefore, there is a significance difference between mean values of the number of citations across different groups. In addition, we calculated Spearsman's rank correlation coefficient (Spearman's Rho) between the number of keywords and citations. The correlation is 0.56 ( $p$ value 0.0001 ) which shows a positive and significant relationship. Taken together, our analysis indicates that there is a strong relationship between the number of keywords and citations that studies in our sample have received. One plausible explanation is that using more keywords increases the likelihood of the study's retrieval and therefore, view and citation by the other researchers. Also, studies with more keywords are likely to cover a wider variety of topics which expands their audience and increases their likelihood of being cited by more studies.

\section{Number of references and number of citations}

Prior studies have argued that there is a positive relationship between the number of references and the number of citations (So et al. 2015). In this section, we aim to verify the reliability of this argument for $\mathrm{KM}$ studies. The minimum, maximum, mean value, and standard deviation of the number of references in our sample are $0,186,57.156$, and 32.152, respectively. We calculated Spearman' Rho correlation which resulted in the value of 0.12 ( $p$ value 0.007 ). The significant and positive correlation demonstrates the impact of the number of references on the number of citations that a study is likely to receive. That is not surprising since a high number of references in a publication indicates that the study has been more rigorously conducted and grounded on the available literature (So et al. 2015).

\section{Number of pages and number of citations}

In this section, we investigate whether there is a significant relationship between the length of the publications in our sample and the number of citations that they have received. The minimum, maximum, mean value, and standard deviation of number of pages are 2, 50, 16.892, and 7.194, respectively. Similar to the previous section, we calculated the Spearman correlation. The Spearman's Rho is 0.18 ( $p$ value 0.0005 ) which again implies a significant and positive impact for the number of pages in a publication on the number of citations that a study is likely to receive. The greater length can reflect scientific complexity and rigorous methodological quality of a publication (Falagas et al. 2013). Additionally, longer articles provide more information that can be cited and referred to by other studies. 
Table 3 Share of different research streams from KM publications

\begin{tabular}{|c|c|c|c|c|}
\hline Research area & $\begin{array}{l}\text { Number of } \\
\text { articles in main } \\
\text { sample }(\%)\end{array}$ & $\begin{array}{l}\text { Number of articles in } \\
\text { subsample of the } 500 \\
\text { most-cited articles }(\%)\end{array}$ & $\begin{array}{l}\text { Number of citations in } \\
\text { subsample of the } 500 \\
\text { most-cited articles }\end{array}$ & $\begin{array}{l}\text { Average } \\
\text { citations } \\
\text { per study }\end{array}$ \\
\hline $\begin{array}{c}\text { Business and } \\
\text { economics }\end{array}$ & $952(29.77 \%)$ & $181(36.2 \%)$ & 15,069 & 83.25 \\
\hline Computer science & $650(20.32 \%)$ & $71(14.2 \%)$ & 7123 & 100.32 \\
\hline $\begin{array}{l}\text { Information and } \\
\text { library science }\end{array}$ & $685(21.42 \%)$ & $69(13.8 \%)$ & 1049 & 15.20 \\
\hline Engineering & $367(11.48 \%)$ & $67(13.4 \%)$ & 1880 & 28.05 \\
\hline $\begin{array}{l}\text { Operations } \\
\text { research and } \\
\text { management } \\
\text { science }\end{array}$ & $174(5.44 \%)$ & $42(8.4 \%)$ & 2254 & 53.66 \\
\hline Psychology & $127(3.97 \%)$ & $16(3.2 \%)$ & 449 & 28.06 \\
\hline Others & $243(7.6 \%)$ & $54(10.8 \%)$ & 2286 & 42.33 \\
\hline
\end{tabular}

\section{Research areas and number of citations}

Although papers in our sample share a KM theme, they can be traced back to different research streams. In fact, scholars from various backgrounds have attempted to apply KM related concepts in their research domains. Therefore, characteristics of these general research streams (e.g., their vitality, popularity, and breadth) can influence the number of citations that articles in our sample have received. Accordingly, we examined the number of citations that studies departing from different research domains have received to identify whether there is a significant difference among different streams with regard to the number of citations. Table 3 demonstrates the share of each research area from total sample (3198 articles) and sub-sample of 500 most-cited articles. The major research areas are business, information and library science, computer science, operational research, engineering, and psychology. As evident by Table 3, KM studies are more common in such fields as business, computer science, and information and library science compared to engineering and medical research.

Table 3 also shows the respective number of total citations and average citations per study within each research area. Interestingly, while the total number of KM articles by "computer science" scholars is lower than that of "business and economics", studies in this domain have a higher average number of citations per study. That can indicate the quality of studies done in this field resulting in important and interesting findings embraced by other researchers. Our results are by and large comparable with those of Serenko and Bontis (2013). However, we should note that the categories that are used to classify the research areas are to some extent different between the two studies. Also, we have extended the sample of articles by drawing our sample from various journals included in WoS database compared to Serenko and Bontis (2013)'s work which was focused on articles published in the Journal of Knowledge Management.

Further, we investigated the time trend of publications in each specific research area. The result has been displayed by Fig. 7. It is important to note that data in Fig. 7 has been extracted from the full sample (3198 articles). It also illustrates how the relative number of publications in each research area has changed between 2000 and 2012. One interesting observation is the dominance of papers from computer science area during 2005-2008. 


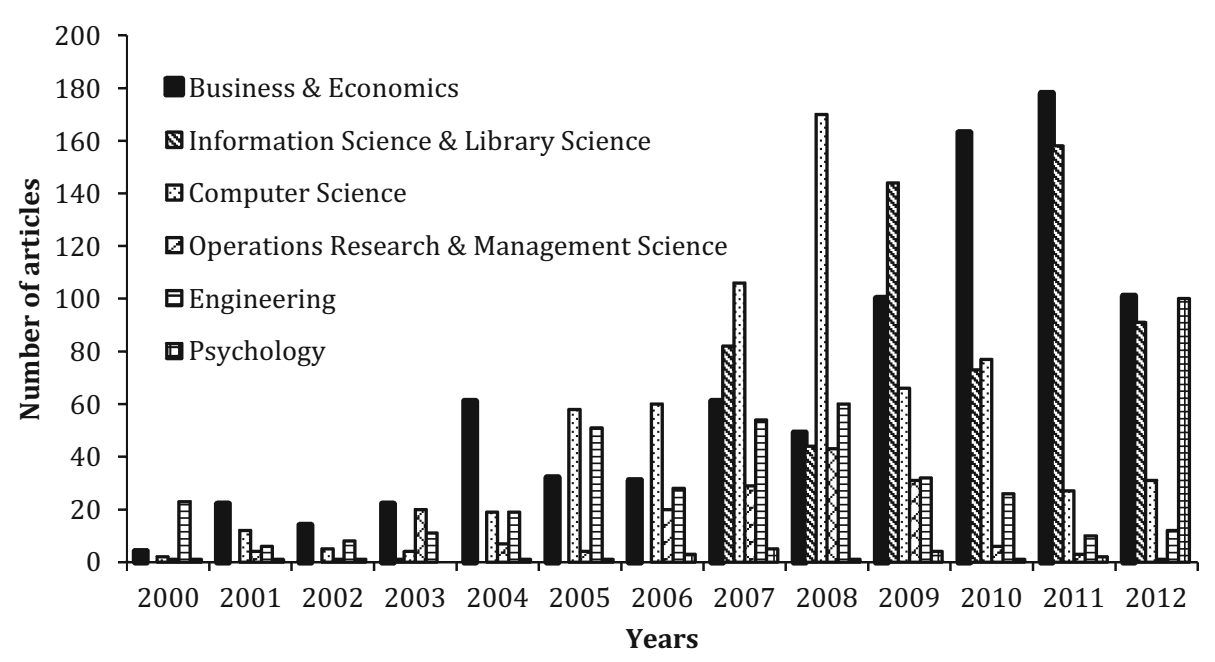

Fig. 7 Number of KM studies based on the research areas/year

Table 4 Number of most cited articles in major journals

\begin{tabular}{ll}
\hline Journals & Number of article \\
\hline Journal of knowledge management & 50 \\
Information and management & 25 \\
International journal of technology management & 22 \\
Technovation & 21 \\
MIS quarterly & 20 \\
\hline
\end{tabular}

However, the number of KM related articles in this domain has been declining since 2008 and since then we have witnessed the dominance of business and economics. That potentially indicates the establishment of KM research as a stand-alone stream within business domain. Another interesting observation drawn from Fig. 7 is a significant increase in KM related studies from psychology researchers that points to a new research venue for scholars to pursue in the future.

\section{Publication outlets and number of citations}

The outlet where an article appears and becomes accessible to other researchers can directly influence its visibility and subsequently the number of times it is cited by other studies (Serenko and Bontis 2013; So et al. 2015). Therefore in this section, we examine whether there is a meaningful relationship between the outlet in which an article is published and the number of citations that it has received. Table 4 shows the journals that have published the highest number of the 500 most-cited articles. The Journal of Knowledge Management is at the top of the list publishing 50 articles.

Further, Fig. 8 reveals the pattern of the number of articles published in each journal over time. According to Adams (2005) and Anderson (1992), citation statistics produced by data from periods shorter than three years may not be sufficiently stable. Therefore Fig. 8 includes articles published up to 2011 allowing three years for a stable citation 


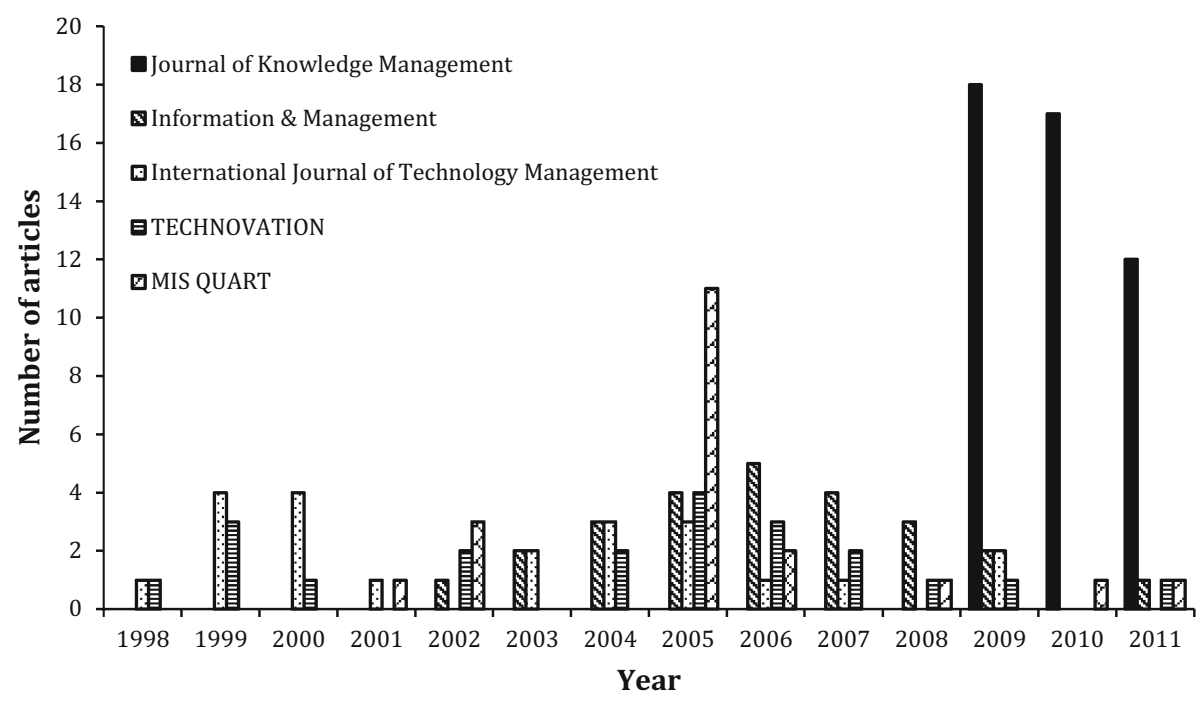

Fig. 8 Number of KM studies published by major outlets/year (the result is extracted from 500 most cited articles)

Table 5 Number of KM publications based on document type

\begin{tabular}{lc}
\hline Type of document & Number of documents \\
\hline Proceedings & 1824 \\
Article & 1189 \\
Review & 63 \\
Editorial material & 50 \\
Book review & 46 \\
Others & 26 \\
\hline
\end{tabular}

index. According to this figure, although outlets such as "Information and Management" and "MIS Quarterly" had the highest rate of publishing the most cited KM papers before 2009, "Journal of Knowledge Management" has been the key outlet for KM studies thereafter. With its exclusive focus on KM topics and the eminent review process that has led to publishing high quality research, Journal of Knowledge Management has become the primary KM journal supporting KM to become an independent research domain.

Finally, as reported in Table 5, we classified the studies in our sample based on different document types. An interesting observation is that unlike Serenko and Dumay (2015a), our sample does not include many review pieces and most of the studies are empirical and conceptual articles.

\section{Discussion}

The aim of conducting bibliometric studies is to encourage a debate among scholars to scrutinize the quality, dimensions, and operationalization of major concepts in a research stream and to provide assistance in evaluating productivity of development process of the 
field (Moed et al. 2002). Information produced by bibliometric studies can be utilized as a source to evaluate the performance of sub-fields in a research domain and to adjust science policies with regard to funding allocations and comparing scientific input and output $(\underline{\mathrm{Gu}}$ 2004). Such studies also provide data on how knowledge flows between different disciplines and creates an opportunity for interdisciplinary studies (Van Leeuwen and Tijssen 2000).

Accordingly, the purpose of our study was to conduct a bibliometric analysis on KM articles in order to identify factors that impact their visibility and citation and to uncover the major trends in this stream. After conducting a comprehensive search process in WoS database and refining the results, we found 3198 relevant articles. Then following prior studies (e.g., Serenko and Dumay 2015a, b), we focused on the most influential studies and conducted our core analyses on the 500 most cited articles. Results of our analyses revealed that number of citations that KM studies in our sample have received has a positive and significant relationship with number of keywords included and the research area from which they originated. That implies the importance of the number of keywords in retrieval of an article. It also acknowledges the fact that studies with more keyword are more likely to cover a wider variety of topics that interest more researchers. Further, we found positive and statistically significant correlation between the number of citations and number of references and pages of the articles in our sample. We did not find any significant differences between single and multi-authored studies in terms of their number of citations. According to our sample, years between 2007 and 2011 have witnessed the highest number of KM publications. Further, research in US and UK still accounts for the majority of studies with highest number of citations.

The novelty of our study is using a more diverse set of keywords and journals to include more articles and research areas undertaking KM studies. Our results have several implications for researchers and policy makers. First, while prior studies had concluded that KM literature was still at a nascent stage due to relatively low contribution of KM specific journals such as Journal of Knowledge Management (Gu 2004), and popularity of normative methods such as literature review among KM studies (Serenko and Dumay 2015a, b), our results revealed that the Journal of Knowledge Management now has the greatest share of the most cited studies in KM literature. Further, as illustrated by Table 5, only a small number of articles in our full sample are review pieces. Finally, increasing share of business and economics in KM literature compared to the dominance of computer science and information and library science in the past is another indication of emergence of KM research in business literature as an independent stream.

Second, our results acknowledge the argument made by previous research that a few developed countries such as US and UK produce the majority of highly cited KM studies (Serenko and Dumay 2015a, b).Our large sample of 3198 articles in addition to a subsample of citation classics (500 most cites articles) enabled us to capture the growing interest in KM studies in other countries such as China and Malaysia. However, their share among the most cited articles is still trivial. While it may imply a lower quality for studies produced in those countries due to factors such as lack of access to quality works or disconnection from scholars in leading countries such as US, it also introduces a great opportunity to science policy makers and research institutions in those countries. Facilitating access to quality research which is increasingly feasible due to advances in databases and their online access, academic exchange programs, and attending international conferences are some examples of effective policies that can help elevate the quality and subsequently visibility of research in countries with growing interest in KM research such as China. 
Third, we observed a decline in single-authored studies over time and a clear trend towards publication of multi-authored articles. Prior scientometric research argues that coauthorship preference is an important phenomenon reflecting the maturity of a scholarly domain (Narin et al. 1991; Inzelt et al. 2009); particularly, there is a positive relationship between the average number of authors per manuscript and the field's maturity (Lipetz 1999). First, as a domain matures, competition for journal space increases and acceptance rates decline. Therefore, inputs from multiple researchers are required to improve the quality of a study in order to ensure its acceptance. Second, researchers may gradually establish their personal research network leading to a higher rate of collaboration. Particularly, collaboration among authors across various countries can create new perspectives in KM literature (Serenko and Dumay 2015a, b). It also leads to creation of specific KM contributions contextualized for various countries and aligned with different domestic idiosyncrasies. It helps to avoid "one size fits all" notion and thus, extending what has worked in countries such as US to other countries which may have completely different characteristics. Cross country studies only represent $8.5 \%$ of our sample which is comparable with $16 \%$ that Serenko and Dumay $(2015 a$, b) found in a similar analysis. That demonstrates a low engagement by KM scholars in international collaborations. However, the growing interest in KM research within several different countries uncovered by our analysis, opens a new window and facilitates international collaborations among KM scholars.

Finally, recent years have witnessed emergence of scholarly interest among scholars from fields such as psychology in KM research. Although we explained that KM has significantly moved towards maturity and independence, it by no means should discourage creation of interdisciplinary studies across different fields. Collaboration among scholars extends the application of KM in various fields, results in more fruitful venues for future studies, and keeps fueling this stream to thrive.

Despite its contributions, this study has some limitations. First, we drew our sample from WoS to enhance the quality and reliability of studies. However, there are other sources and outlets that have been growing in recent years and are not indexed by WoS. In fact, several of KM centric journals such as International Journal of Knowledge Management, Journal of Information and Knowledge Management, and Knowledge and Process Management: The Journal of Corporate Transformation have not been indexed by WoS. Therefore, in order to create consistency and enhance the quality of studies included in our sample, we might have missed several KM specific outlets. Second, to be more focused, we only included the 500 most cited papers in our core analysis. We acknowledge that including more studies may change the results which is a viable venue for future studies to examine. Third, while we have found significant and meaningful relationships between some characteristics of the studies in our sample (e.g., number of keywords, pages, and references) and number of citations that they have received, we, by no means, argue for a causation relationship. Future studies using primary data from KM scholars can investigate what characteristics lead them to cite an article and compare the results with those of our study to uncover the true causal relationships. Finally, studies from US and UK consist the majority of our sample. Thus, our results and interpretation of citation behavior of KM scholars might be biased towards those prolific countries and may not completely apply to scholars in other countries.

Acknowledgments Authors would like to express their special thanks to anonymous reviewers that really enriched this research with their valuable comments by three rounds of review. 


\section{References}

Adams, J. (2005). Early citation counts correlate with accumulate impact. Scientometrics, 63(3), 567-581. Anderson, E. (1992). Japanese firms emphasize technology management. Chemical \& Engineering News, $70(40), 46-48$.

Bjørnson, F. O., \& Dingsøyr, T. (2008). Knowledge management in software engineering: A systematic review of studied concepts, findings and research methods used. Information and Software Technology, 50(11), 1055-1068.

Crilly, T., Jashapara, A. \& Ferlie, E. (2009). Research utilization and knowledge mobilisation: a scoping review of the literature. Draft report, SDO, Southampton.

Eshraghi, A., Osman, N., Gholizadeh, H., Ali, S., \& Shadgan, B. (2013). 100 top-cited scientific papers in limb prosthetics. BioMedical Engineering OnLine, 12(1), 1-12.

Falagas, M. E., Zarkali, A., Karageorgopoulos, D. E., Bardakas, V., \& Mavros, M. N. (2013). The impact of article length on the number of future citations: a bibliometric analysis of general medicine journals. PLoS ONE, 8(2), e49476.

Garfield, E. (1972). Citation analysis as a tool in journal evaluation. Science, 178, 471-479.

Gu, Y. (2004). Global knowledge management research: A bibliometric analysis. Scientometrics, 61(2), 171-190.

Guo, Z., \& Sheffield, J. (2008). A paradigmatic and methodological examination of knowledge management research: 2000 to 2004. Decision Support Systems, 44(3), 673-688.

Ida, T., \& Fukuzawa, N. (2013). Effects of large-scale research funding programs: A Japanese case study. [Article]. Scientometrics, 94(3), 1253-1273.

Inzelt, A., Schubert, A., \& Schubert, M. (2009). Incremental citation impact due to international coauthorship in Hungarian higher education institutions. Scientometrics, 78(1), 37-43.

Kane, H., Gillian, R., \& Charles, O. (2006). Knowledge management methodologies. The Electronic Journal of Knowledge Management, 4(2), 141-152.

Karami, A., Rowley, J., \& Analoui, F. (2006). Research and knowledge building in management studies: An analysis of methodological preferences. International Journal of Management, 23(1), 43-52.

Lipetz, B. A. (1999). Aspects of JASIS authorship through five decades. Journal of the American Society for Information Science, 50(11), 994-1003.

Marks, R. H. (2001). Learned societies adapt to new publishing realities. In E. Fredrickson (Ed.), A Century of Science Publishing: A Collection of Essay (pp. 91-96). Amsterdam: IOS Press.

Moed, H. F., Luwei, M., \& Nederhof, A. J. (2002). Towards research performance in the humanities. Library Trends, 50(3), 498-520.

Narin, F., Stevens, K., \& Whitlow, E. S. (1991). Scientific co-operation in Europe and the citation of multinationally authored papers. Scientometrics, 21(3), 313-323.

Nicolini, D., Powell, J., Conville, P., \& Martinez-Solano, L. (2008). Managing knowledge in the healthcare sector: A review. International Journal of Management Reviews, 10(3), 245-263.

Nonaka, I., \& Peltokorpi, V. (2006). Objectivity and subjectivity in knowledge management: A review of 20 top articles. Knowledge and Process Management, 13(2), 73-82.

Ponce, F. A., \& Lozano, A. M. (2010). Highly cited works in neurosurgery. Part I: The 100 top-cited papers in neurosurgical journals: A review. Journal of Neurosurgery, 112(2), 223-232.

Ponzi, L. (2002). The intellectual structure and interdisciplinary breadth of knowledge management: A bibliometric study of its early stage of development. Scientometrics, 55(2), 259-272.

Qiu, J., \& Lv, H. (2014). An overview of knowledge management research viewed through the web of science (1993-2012). Aslib Journal of Information Management, 66(4), 424-442.

Rezazadeh Mehrizi, M. H., \& Bontis, N. (2009). A cluster analysis of the KM field. Management Decision, 47(5), 792-805.

Scandura, T. A., \& Williams, E. A. (2000). Research methodology in management: Current practices, trends, and implications for future research. Academy of Management Journal, 43(6), 1248-1264.

Schultze, U., \& Leidner, D. E. (2002). Studying knowledge management in information systems research: Discourses and theoretical assumptions. MIS Quarterly, 26(3), 213-242.

Schultze, U., \& Stabell, C. (2004). Knowing what you don't know? Discourses and contradictions in knowledge management research. Journal of Management Studies, 41(4), 549-573.

Serenko, A. (2013). Meta-analysis of scientometric research of knowledge management: discovering the identity of the discipline. Journal of Knowledge Management, 17(5), 773-812.

Serenko, A., \& Bontis, N. (2013). The intellectual core and impact of the knowledge management academic discipline. Journal of Knowledge Management, 17(1), 137-155. 
Serenko, A., Bontis, N., Booker, L., Sadeddin, K., \& Hardie, T. (2010). A scientometric analysis of knowledge management and intellectual capital academic literature (1994-2008). Journal of Knowledge Management, 14(1), 3-23.

Serenko, A., \& Dumay, J. (2015a). Citation classics published in knowledge management journal. Part I: Articles and their characteristics. Journal of Knowledge Management, 19(2), 401-431.

Serenko, A., \& Dumay, J. (2015b). Citation classics published in knowledge management journal. Part II: Studying research trends and discovering the Google Scholar Effect. Journal of Knowledge Management, 19(6), 1335-1355.

So, M., Kim, J., Choi, S., \& Park, H. W. (2015). Factors affecting citation networks in science and technology: focused on non-quality factors. Quality \& Quantity, 49(4), 1513-1530.

Thelwall, M. (2008). Bibliometrics to webometrics. [Review]. Journal of Information Science, 34(4), $605-621$.

Tsai, Y. L., Lee, C. C., Chen, S. C., \& Yen, Z. S. (2006). Top-cited articles in emergency medicine. The American Journal of Emergency Medicine, 24(6), 647-654.

Van Leeuwen, T., \& Tijssen, R. (2000). Interdisciplinary dynamics of modern science: Analysis of cross disciplinary citation flows. Research Evaluation, 9(3), 183-187.

Wildgaard, L. (2015). A comparison of 17 author-level bibliometric indicators for researchers in Astronomy, Environmental Science, Philosophy and Public Health in Web of Science and Google Scholar. Scientometrics, 104(3), 873-906. 